\title{
The "New Generation" High-tech Enterprise's Early Warning Model and Its Empirical Research Based on the Perspective of Organizational Commitment Theory
}

\author{
Huabai Bu ${ }^{1,2}$, Jiaqi $\mathrm{Bu}^{2}$, Naifu Shi ${ }^{2}$, Lingli OuYang ${ }^{2} \&$ Jingyi Wang ${ }^{2}$ \\ ${ }^{1}$ Hengyang Normal University, China \\ ${ }^{2}$ Krirk University, Thailand \\ Correspondence: Huabai Bu, Hengyang Normal University, Hengyang 421008, Hunan, China.
}

Received: August 13, 2021

Accepted: September 2, 2021

Online Published: September 15, 2021

doi:10.5539/ibr.v14n10p96

URL: https://doi.org/10.5539/ibr.v14n10p96

\begin{abstract}
With the continuous advancement of emerging technologies such as big data, cloud computing, Internet of Things, blockchain, artificial intelligence, and 5G communications, China's "new generation" high-tech companies are developing rapidly, but the loss of core employees restricts their healthy development. How to manage the core employees of "new generation" high-tech enterprises is a grim reality in front of theorists and industrialists. Based on the results of the current theoretical research on organizational commitment, the research group proposed a "new generation" high-tech enterprise core employee resignation early warning model to provide decision-making basis and methodological reference for the "new generation" high-tech enterprise high-quality development.
\end{abstract}

Keywords: organizational commitment, enterprise core employees, resignation early warning, model application

\section{Research Background}

With the advent of the fourth industrial revolution, emerging technologies represented by big data, cloud computing, Internet of Things, blockchain, artificial intelligence, 5G communications, etc. have developed rapidly(Sun Dian, Xue Lan, Zhang Lupeng,2021), it is detonating "new generation" high-tech companies continued growth. High-tech talents are a mobile element that maintains the destiny of high-tech enterprises. Under this background, the competition for high-tech talents is becoming increasingly fierce. As a result, the loss of high-tech talents has become a major threat to the healthy development of high-tech enterprises. To manage the core employees of "new generation" high-tech enterprises is a grim reality in front of theorists and industrialists.

At present, more and more researchers have found that organizational commitment is the basis and source of many management measures, especially human resource management measures. It can not only explain the relationship between many variables in the enterprise organization, but also forecast work performance, absenteeism, sabotage, resignation tendency, willingness to stay and many other issues that human resource managers care about. The "new generation" high-tech enterprise's core employee resignation early warning model discussed in this article, as an applied human resource management model, is also based on the theory of organizational commitment. It will provide theoretical basis for decision-making and operational realization.

\section{Literature Review and Theoretical Basis}

\subsection{Literature Review}

Organizational commitment theory was born in the early 1960s, and its representatives mainly include Becker, Porter, Smith, Steers, Allen, Meyer, Stevens, etc. Since the concept of organizational commitment was put forward by Becker in 1960, the theoretical and practical circles have different conclusions on its connotation. Becker (1960) believes that organizational commitment is generated by exchange considerations. Organization members often compare their own contributions to the rewards they receive from the organization between the organization and the relationship, and believe that this exchange process is beneficial to them, so the individual's commitment to the organization will increase, otherwise, its commitment to the organization will decrease(Becker H A,1960). Angle and Perry(1983) have also done in-depth research on the connotation of 
organizational commitment. Angle and Perry (1981) found that organizational commitment is related to organizational adaptability, resignation and procrastination rate, and has nothing to do with operating costs or absenteeism. When analyzing the relationship between organizational commitment and resignation time, Becker (1996) found that the relationship between the two is the strongest before the individual is about to leave the organization. When comparing organizational commitments, Becker (1992), Porter (1974), etc. found that supervisory commitments have a stronger positive correlation with job performance, and that commitments to senior managers and supervisors are more effective than emotional commitments to job satisfaction, willingness to leave and pro-organization. Ritzer and Trice (1969) examined the relationship between eight factors such as age, education and marital status and organizational commitment, and found that only the company's internal rate of change and income have a significant positive correlation with organizational commitment. Alutto (1973) and others improved the questionnaires of Ritzer and Trice and found that gender and working years are significantly positively correlated with organizational commitment. Steers(1977) found that organizational commitment is related to the increase in willingness to stay. So far, the explanation accepted by most people is the three-dimensional structure model proposed by Canadian scholars Allen and Meyer (1990), that is, there are three forms of organizational commitment: emotional commitment, continuation commitment and normative commitment. Eby (1999) and other studies have shown that feedback and autonomy have a direct positive impact on emotional commitment. Work degenerative tendency is one of the outcome variables of organizational commitment. Somers (1995) research shows that affective commitment and normative commitment are significantly negatively correlated with work degenerative tendency, and the interaction between continuous commitment and affective commitment can predict work degenerative tendency. The study by Tsoumbris and Xenikou (2010) found that employees with high emotional commitments, normative commitments, and continuous commitments are less likely to leave and change jobs than employees with low commitments and continuous commitments, and their organizational citizenship behavior scores are higher than emotional promises and norms are led by employees. However, as an applied research of this theory, this article is more concerned with the formation mechanism of organizational commitment and its consequences for enterprise management. To this end, we then discuss two important theoretical models of organizational commitment theory.

\subsection{Theoretical Basis}

\subsubsection{Antecedents and Effects Model of Organizational Commitment}

The antecedent and outcomes model of organizational commitment was proposed by Steers in the paper "Antecedents and outcomes of organizational commitment" published in 1977. He believed that the antecedents of organizational commitment, or predictive variables, mainly include personal characteristics 、 work characteristics and work experience; the results of organizational commitments, or benchmark variables, mainly include willingness to stay, attendance and work performance. Steers(1977) and Mowday (1979) improved their models and believed that there are four types of predictive variables: personal characteristics, character-related characteristics, structural characteristics, and work experience; while there are five types of standard variables: work Performance, the length of the core staff's tenure, slow work, absenteeism, and personnel resignation rate. This improved model qualitatively illustrates the relationship between the antecedents and results of organizational commitments, thereby providing a qualitative analysis tool for the improvement of corporate performance and the management of core employee retention.

\begin{tabular}{|c|c|c|}
\hline Personal & \multirow{3}{*}{$\begin{array}{l}\text { Organizational } \\
\text { commitment }\end{array}$} & work performance \\
\hline characteristics & & Absence \\
\hline About character & & Sabotage \\
\hline Structure & & Personnel Change Rate \\
\hline
\end{tabular}

Figure 1. The improved antecedent and result model of organizational commitment

\subsubsection{Role Perception Model of Organizational Commitment}

Among the theoretical models of organizational commitment, another representative theoretical model is the role perception model of organizational commitment proposed by Stevens etal. They believe that the organizational commitments of psychological and exchange views should be considered comprehensively aiming at organizational members' relevant factors of organizational affiliation or resignation. Due to this reason, they 
have established an organizational commitment role perception model to explain the core employees' willingness to stay and resignation tendency. The specific process is shown in Figure 2.

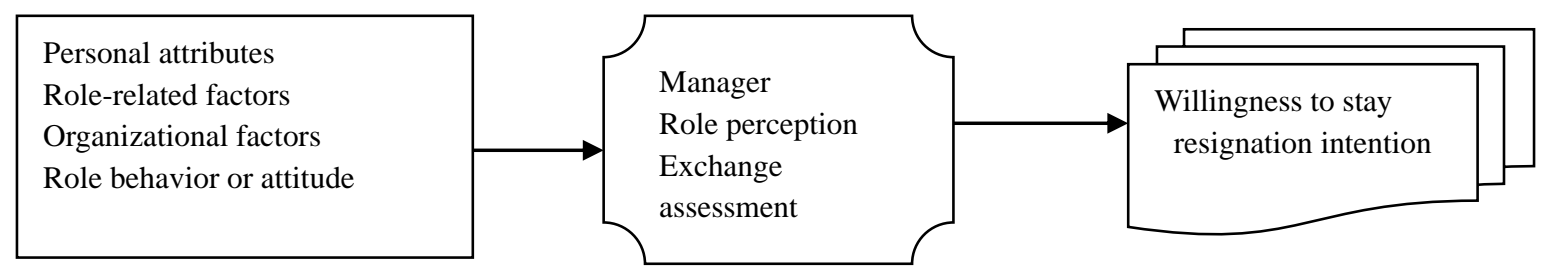

Figure 2. Organizational commitment role perception model

At the same time, they also believe that in the early stages of their careers, due to their relatively low age and experiences, their organizational commitments are mainly affected by psychological or personal factors; With the increase in age and experiences, the importance of personal factors decreases, and ancillary benefits gradually gain influence increases, and the cost that members have to pay for leaving the organization increase ,and the organization gains a certain degree of commitment from members. Although members will stay in the organization, they will devote their efforts to gaining other benefits outside the organization. At this time, the members' commitment to the organization changes from the psychological organizational commitment when they first entered the organization to the exchange based on practical considerations. In this regard, related studies include Zhang Yunsheng (2019), Zeng Deming(2020), Zou Siming (2020), etc. They study the working environment and organizational behavior of core employees of high-tech enterprises from the aspects of innovation ecology of high-tech enterprises. To a certain extent, these studies reflect the organizational commitment of the core employees of high-tech enterprises.

\section{Empirical Research}

\subsection{Research Objects}

High-tech enterprises are the main force that promotes industrial development and technological progress, and are innovative highs where technology and economic and technological needs are closely integrated. The "14th Five-Year Plan" period is a critical period for Hengyang to become a strong city in technological innovation and a sub-provincial central city in southern Hunan. Therefore, cultivating and retaining innovative talents for the "new generation" of high-tech enterprises will play a significant role in the development of Hengyang. For the above reasons, the research team selected Hengyang "new generation" high-tech enterprises as the research sample.

\subsection{Data Acquisition}

In order to fully and accurately understand the influencing factors that affect the loss of core employees of the "new generation" high-tech enterprises, the research team organized an investigation from April 2021 to May 2021. The object of the investigation was the "new generation" high-tech enterprises in Hengyang. The core employees of the company was distributed 510 relevant research questionnaires and returned 493 questionnaires. The questionnaire recovery rate was $96.67 \%$.

\subsection{Variable Factor Analysis}

\subsubsection{Organizational Commitment}

According to the theory of organizational commitment, the strength of organizational commitment of core employees is mainly manifested in the following four aspects: (1) Personal factors, including age, seniority, education, gender, race and personal health, etc.; (2) Work factors, including position High and low, overwork, organizational length, position, working skills, promotion, challenge, job integrity, etc.; (3) Organizational factors, including organization size, control range, power concentration, organizational reliance, Group norms, organization scale, trade union involvement, group attitudes, degree of trust in the organization, personal importance, etc.; (4) The characteristics of the relevant roles, including the scope and challenge of work, role conflicts, and role confusion. These four aspects affect the strength of the core employees' organizational commitments to varying degrees.

In view of these four aspects, the research team added two factors of the abundance of personal social resources and learning ability to the personal factors, and increased the maturity of the production technology of the enterprise and the importance the enterprise attaches to industry-university-research in the organizational factor, 
using factor analysis method conducted a statistical analysis on the collected 496 questionnaire data, and found that the level of education, the abundance of personal social resources, the size of the workload, the degree of organizational dependence, the maturity of enterprise production technology, the role conflict and role confusion, and the trust in the organization and the degree of group standardization have a greater impact on the strength of the core employees' organizational commitment.

\subsubsection{External Opportunities}

The resignation tendency of core employees is affected by the number of external development opportunities . There are five factors that affect the number of external opportunities for core employees: (1) Industry development cycle. If the industry is in a period of rapid growth, there will be many external opportunities for core employees, but if the industry has entered a mature period, or even in a period of recession, there will be few external opportunities for core employees. (2) Industry competition structure. If the industry competition structure is basically stable, there will be fewer external opportunities for core employees, and vice versa, higher; (3) The demand for industry professionals; (4) Industry professional intermediary companies; (5) Macroeconomics, mainly including macroeconomics development cycle and national industrial economic policies.

In view of these five aspects, the research team also used factor analysis to analyze the collected 496 questionnaire data and found that the industry is in a period of rapid growth, industry intermediary companies appear, national industry support policies are promulgated, and a major competitor is expanding, the good macroeconomic development situation and other factors have a greater impact on the external development opportunities of core employees.

\subsection{Variable Measurement}

From the previous analysis, we can see that there are many factors that affect the resignation intention of core employees. On the one hand, these influencing factors have different importance on the resignation intention of core employees, that is, the weight is different; on the other hand, some factors mainly affect resignation intention. Some factors mainly affect retention tendency, and some affect both. It is this kind of consideration that we must continue to determine the weights and scores of various factors that affect resignation intention.

\subsubsection{Weight Determination}

Here, the weight is used to indicate the importance of each factor's influence on the behavior of core employees. If a factor has a great influence on the behavior of core employees, regardless of whether it affects the retention or departure of core employees, this factor must be given a higher weight. This study uses the principal component analysis method to calculate the weight of each impact factor.

\subsubsection{Determining the Score}

The research team invited 15 experts, core employees and senior executives (including 5 experts researching the development of high-tech enterprises, 5 core employees of high-tech enterprises, and 5 senior executives of high-tech enterprises). Each factor that affects resignation intention is scored (1-4 points), and its value is based on the four levels of main retention factors, secondary retention factors, secondary resignation factors, and main resignation factors, which are assigned 1 point, 2 points, 3 points and 4 points, and finally take their average score as the final assignment.

\subsection{Early Warning Model Construction}

Suppose the total number of core employees of the enterprise is $\mathrm{N}$, the total number of organizational commitment factors that affect the resignation intention of core employees of the enterprise is $\mathrm{M}$, the external development opportunity factor is $\mathrm{T}$, and the influence weight of the a-th organizational commitment factor of the $\mathrm{i}$-th employee is $\mathrm{w}_{\mathrm{ia}}$, assignment size is $\mathrm{q}_{\mathrm{i}}$, the comprehensive weight is $\mathrm{X}_{\mathrm{i}}$, the influence weight of the $\mathrm{b}$-th external development opportunity factor of the $\mathrm{i}$-th employee of the enterprise is the $\mathrm{w}_{\mathrm{ib}}$, assignment size is $\mathrm{q}_{\mathrm{ib}}$, and the comprehensive weight is $\mathrm{Y}_{\mathrm{i}}$, the enterprise's core employee resignation early warning model is:

$$
\begin{aligned}
& \mathrm{X}_{\mathrm{i}}=\sum \mathrm{w}_{\mathrm{ia}} \mathrm{q}_{\mathrm{ia}} \\
& \mathrm{Y}_{\mathrm{i}}=\sum \mathrm{w}_{\mathrm{ib}}, \mathrm{q}_{\mathrm{ib}}
\end{aligned}
$$

Where $\mathrm{i}=1,2,3, \ldots, \mathrm{N} ; \mathrm{a}=1,2,3, \ldots, \mathrm{M} ; \mathrm{b}=1,2,3, \ldots, \mathrm{T}, 0<\mathrm{w}_{\mathrm{i} a},<1,0<\mathrm{w}_{\mathrm{ib}},<1$, the assignment of $\mathrm{q}_{\mathrm{ia}}$ and $\mathrm{q}_{\mathrm{ib}}$ is based on the average situation of the industry in which the enterprise is located, and is carried out according to the degree of influence.

Assuming that the score is divided into four levels: "primary retention factor", "secondary retention factor", 
"secondary resignation factor", and "primary resignation factor", assigning values 1, 2, 3, and 4 respectively, then:

$$
\begin{gathered}
1 \leq \mathrm{q}_{\mathrm{ia}} \leq 4, \quad 1 \leq \mathrm{q}_{\mathrm{ib}} \leq 4 \\
\text { Because } \sum \mathrm{w}_{\mathrm{ia}}=1 \text { and } \sum \mathrm{w}_{\mathrm{ib}}=1 \text {, so } 1 \leq \sum \mathrm{w}_{\mathrm{ia}} \mathrm{q}_{\mathrm{ia}} \leq 4,1 \leq \sum \mathrm{w}_{\mathrm{ib},} \mathrm{q}_{\mathrm{q} b} \leq 4
\end{gathered}
$$

Taking $X$ as the comprehensive weighted number of resignation intentions caused by organizational commitment factors and $\mathrm{Y}$ as the comprehensive weighted number of resignation intentions caused by external development opportunity factors, the $(\mathrm{X}, \mathrm{Y})$ distribution map of $\mathrm{N}$ core employees can be drawn, and the distribution map can be used to early warning analysis of the resignation of core employees of the enterprise, so as to provide decision-making basis for the enterprise to formulate the management strategy of core employees.

In order to more intuitively reflect the overall quantitative distribution characteristics of the organizational commitments and external opportunities of the core employees in the enterprise, we can draw a model diagram. Because $1 \leq \sum \mathrm{w}_{\mathrm{ia}} \mathrm{q}_{\mathrm{ia}} \leq 4,1 \leq \sum \mathrm{w}_{\mathrm{ib}}, \mathrm{q}_{\mathrm{ib}} \leq 4$, we can roughly divide it into three segments on the $\mathrm{X}$ and $\mathrm{Y}$ axes according to the comprehensive weights of the various factors of the organization's commitment and the comprehensive weights of the factors of external opportunities, namely Weak 0[1. 00 2.00), average [2. $00 \sim 3.00$ ), strong [3. 00 4.00], so that nine squares are obtained on a two-dimensional plane, and each square represents a different combination of external opportunities. In this way, we can draw the core employee departure warning model diagram, as shown in Figure 3:

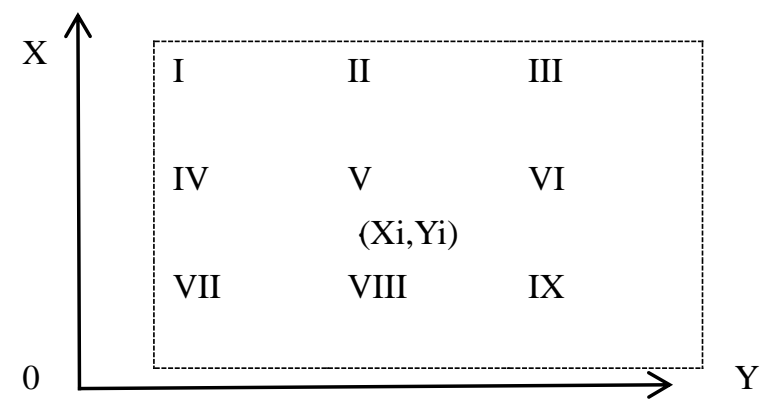

Figure 3. Analysis diagram of the early warning model of core employee resignation

\section{Case Study}

The relevant methods and data processing have been analyzed above, and then we will take the "new generation" electronic information technology enterprises in Hengyang City as a case to study. The "new generation" electronic information technology enterprises in Hengyang.

For the convenience of research, the first company included in the research of the research group is numbered "A". The "A" company has 12 core employees in total, numbered in the order of 1-12. According to the method provided above, the first step calculate the weights, scores and weighted total dimension $A_{1}\left(X_{1}, Y_{1}\right)$ of the organizational commitment factors and external opportunity factors of the core employees (Zhang San) of "A" enterprise "No. 1", as shown in Table 1. and table 2.

Table 1. Comprehensive weighted number of resignation intentions of core employees of "A" enterprise "No. 1 "X $\mathrm{X}_{1}$

\begin{tabular}{|l|c|c|c|}
\hline Organizational commitment factor & ${\text { Weights } \mathrm{w}_{1 \mathrm{a}}}$ & Points $\mathrm{q}_{1 \mathrm{a}}$ & $\mathrm{X}_{1}$ \\
\hline Education level & 0.25 & 4 & 1 \\
\hline Heavy workload & 0.05 & 1 & 0.05 \\
\hline Abundance of personal social resources & 0.15 & 3 & 0.45 \\
\hline Organization dependent & 0.15 & 3 & 0.45 \\
\hline Trust in the organization & 0.18 & 3 & 0.54 \\
\hline Group norms & 0.12 & 2 & 0.24 \\
\hline Role conflict and confusion & 0.10 & 2 & 0.20 \\
\hline Sum & 1.00 & & 2.93 \\
\hline
\end{tabular}


Table 2. Comprehensive weighted number $Y_{1}$ of external development opportunity factors for core employees of "A" company "No. 1"

\begin{tabular}{|l|c|c|c|}
\hline External development opportunity factors & Weights $\mathrm{w}_{1 \mathrm{~b}}$ & Points $\mathrm{q}_{1 \mathrm{~b}}$ & $\mathrm{Y}_{1}$ \\
\hline Industry development is in a period of rapid growth & 0.20 & 3 & 0.60 \\
\hline National industry support policy is promulgated & 0.15 & 1 & 0.15 \\
\hline The emergence of industry intermediary companies & 0.15 & 3 & 0.45 \\
\hline Expansion of a major competitor & 0.30 & 3 & 0.90 \\
\hline The macroeconomic development situation is good & 0.20 & 1 & 0.20 \\
\hline Sum & 1.00 & & 2.3 \\
\hline
\end{tabular}

Similarly, for the core employees numbered $2,3, \ldots, 12$ are calculated respectively, $A_{2}\left(X_{2}, Y_{2}\right) 、 A_{3}\left(X_{3}, Y_{3}\right) 、 A_{4}$ $\left(X_{4}, Y_{4}\right) 、 A_{5}\left(X_{5}, Y_{5}\right) 、 A_{6}\left(X_{6}, Y_{6}\right) 、 A_{7}\left(X_{7}, Y_{7}\right) 、 A_{8}\left(X_{8}, Y_{8}\right) 、 A_{9}\left(X_{9}, Y_{9}\right) 、 A_{10}\left(X_{10}, Y_{10}\right) 、 A_{11}\left(X_{11}, Y_{11}\right) 、$ $A_{12}\left(X_{12}, Y_{12}\right)$, and finally get the position distribution diagram of the comprehensive weighted number of core employees of the enterprise in the early warning model the diagram is shown in Figure 5.

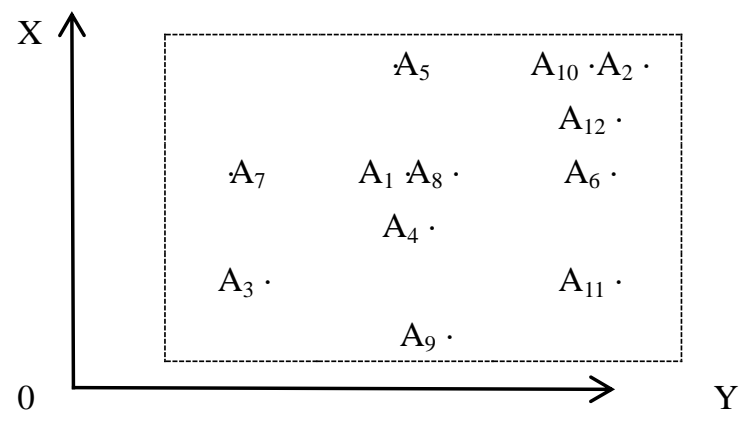

Figure 5. "A" enterprise core employee resignation early warning model analysis diagram

It can be seen from the distribution diagram that the 12 core employees of A company are mainly distributed in the upper right corner of four intervals in the early warning model, indicating that the external development opportunities and resignation intentions of the company's core employees are generally too large, and the resignation of core employees must attach great importance. Specifically, in box III, the core employees $\mathrm{A}_{10}, \mathrm{~A}_{2}$, and $\mathrm{A}_{12}$ have large resignation intentions, and there are many opportunities for external development. For this part of core employees, the company must carefully maintain their existing level of organizational commitment and the possibility of loss is very large.

The employees that the company needs to pay special attention to are $\mathrm{A}_{1}, \mathrm{~A}_{8}$ and $\mathrm{A}_{4}$ in Box $\mathrm{V}$, Companies should strengthen communication based on their resignation factors as much as possible to help solve their actual problems and promote the transformation to the direction of VII. In box II, $\mathrm{A}_{5}$ is also not stable employees, resignation intention due to organizational psychological commitment factors is large, but their external development opportunities are medium; in box IX, $\mathrm{A}_{11}$ has low resignation intention, but there are many opportunities for external development. Such employees can increase their training efforts to make him plays a greater role in the development of the enterprise; in box VII, the organizational commitment and external development opportunities of core employees $\mathrm{A}_{3}$ are small, and for this part of core employees, the efforts must be made to cultivate their organizational commitment, otherwise they will quickly quit.

\section{Findings and Suggestions}

Emerging technologies such as big data, cloud computing, Internet of Things, blockchain, artificial intelligence, and $5 \mathrm{G}$ communications have continuously spawned a large number of "new generation" high-tech enterprises. However, the high resignation rate of core technical employees of the "new generation" high-tech enterprises has brought serious threats about enterprise development. The management significance of the "new generation" high-tech enterprise core employee resignation early warning model is that the model provides the corporate human resources department with a stable distribution map of the core employee team of the enterprise, it has at least the following four aspects of enlightenment for the management of the core staff team of the enterprise: 


\subsection{Focus on the Analysis of the Resignation Tendency Factors of the Core Employees of the "New Generation" High-Tech Enterprises, Oppose the "One Size Fits All" in the Formulation of Human Resources Policies, and Comprehensively Stabilize the Core Employees Team}

For the analysis of the factors affecting the resignation tendency of core employees of "new generation" high-tech enterprises, the research team believes that not only the strength of the core employees' internal organizational commitments, but also the number of opportunities for external core employees to find jobs, the two factors collectively determine the tendency of core employees to leave the company. According to the investigation of our research group, many companies currently formulate unified human resource policies. This practice often "failures" because the reasons for core employees' resignation are different, the intensity of resignation tendencies are different, and the opportunities for external development are also different. This requires companies to adopt different human resource policies for different situations, and resolutely oppose the "one size fits all" in the formulation of human resources policies in order to comprehensively stabilize the core workforce.

The specific approach is to first delineate the core employees of the company into I IX according to the model, and then take targeted management strategies based on their location characteristics in the model diagram.The decision-making level of the company must resolutely oppose manpower "One size fits all" policy in order to comprehensively stabilize the core employees of the "new generation" high-tech enterprise.

5.2 Pay Attention to the Dynamic Adjustment in the Implementation of the Human Resources Policy, Oppose the Excessive Rigidization in the Implementation of the Human Resources Policy, and Comprehensively Stabilize the Core Employees of the "New Generation" High-Tech Enterprise

With the continuous changes of core employees' economic conditions, social status, and interpersonal relationships, the psychological needs of core employees are also constantly changing. If an enterprise wants to stabilize its core workforce, it must carefully study the dynamic laws of its core employees' psychological changes, and give this kind of psychological satisfaction in time, so as to raise the minimum level of maintaining the organizational commitment of core employees.

In addition, when factors such as the size of the company and group attitudes change, the level of organizational commitment of core employees will also change, this requires that the human resources policy must be dynamically adjusted during the implementation of the human resource policy, opposed to excessive rigidity in the implementation of the human resource policy, and comprehensively stabilize the core workforce of the "new generation" high-tech enterprise.

5.3 Pay Attention to the Whole Process of the Management of the Core Employees of the "New Generation" High-Tech Enterprises, and Advocate the Prevention of Gradual Failure in the Implementation of the Human Resources Policy, and Reduce the Resignation Rate of Outstanding Talents.

The cultivation of core employees' organizational commitment is a continuous process. At different stages of this process, the main factors that affect the core employees' organizational commitment are different. Therefore, "new generation" high-tech enterprises must establish a full-process management system for organizational commitment. Specifically, in the initial stage of the core employees' entry, the company should pay close attention to the core employees' attitudes towards the organization, and measure the core employees' organizational commitments in a timely manner, so as to maximize the grasp of the core employees' psychological trends and take effective measures to control the core employee resignation rate.

When core employees are gradually integrated into the organizational role, the company must cultivate the organizational commitment of the core employees step by step to prevent gradual failure, and reduce the resignation rate of outstanding talents. Once the core employees enter the resignation stage, the company should also talk to the resigning core employees, listen to their evaluation opinions on the organization, and grasp the reasons for their resignation, and lay the foundation for strengthening the management of the core employees' organizational commitments in the future. Only in this way can the company provide guarantee for the sustainable development of the talent echelon of "new generation" high-tech enterprises.

5.4 Pay Attention to the Difference in the Value System between Employees and the "New Generation" High-Tech Enterprises, Advocate the Creation of a Good Soft Environment for Core Employees, and Reduce the Resignation Rate of Outstanding Talents.

When a core employee joins an enterprise, the process of identifying with the corporate culture and forming a unified value is a process of "obedience $\rightarrow$ identification $\rightarrow$ assimilation $\rightarrow$ internalization", which requires the "new generation" high-tech enterprises to pay attention to the value system of both employees and enterprises 
from the beginning of recruitment, it is necessary to strengthen the selection of core employees, that is, priority should be given to selecting core employees who agree with the corporate culture.After they enter the company, they have to be trained, evaluated and other measures to make them recognize, assimilate and internalize this culture, and finally achieve the unity of corporate values and personal values, thereby creating a good soft environment for the core employees of the "new generation" of high-tech enterprises, improving their organizational commitment level, and reducing the resignation rate of outstanding talents.

Today in the 21 st century, the most important management ability is no longer capital management ability, but knowledge management ability. Therefore, whether the "new generation" high-tech enterprise can manage its core employees well will be the key to the success or failure of the enterprise's future competition. Although this view has become a consensus, the issue of how to manage the core employees of "new generation" high-tech enterprises still needs to be deepened in theory and practice.

\section{Acknowledgement}

This article is co-funded by the projects of 2021 Hunan Provincial Natural Science Foundation Project "Hengyang High-tech Enterprise Value Network Blockchain Embedding, Collaborative Innovation Model and Collaborative Innovation Performance Research-Take the "new generation" information technology enterprise as an example"(2021JJ50072); 2021 Hunan Innovative Province Construction Special project "Research on Audience Demand, Innovation Path and Coping Strategy of Popular Science Base in the Era of intelligent media --- A case study of 91 Popular Science bases in Hunan Province"; 2019 Hengyang Science and Technology Plan Fund Project "Hengyang '14th Five-Year' Science and Technology Development Preliminary Research"; 2020 Hengyang City Science and Technology Plan Fund Project "Hengyang City Research on the Strategic Layout of Scientific and Technological Innovation and Its Implementation Strategies"; 2019 Hengyang Science and Technology Plan Fund Project "Hengyang High-tech Enterprise Development Research"; 2020 Hengyang Social Science Fund Project "Hengyang Emerging Industry Network Embedded Selection and Development under the Background of 5G Research on Positioning and Development Consequences" (2020B(II)004).

\section{References}

Allen, N. J., \& Meyer, J. P. (1990). The measure meat and antecedents of affective, continuance and normative commitment to the organization. Journal of Occupational Psychology, 63, 1-18. https://doi.org/10.1111/j.2044-8325.1990.tb00506.x

Alutto J. A., Hrebiniak L. G., \& Alonso R. C. (1973). On Operation the Concept of Commitment. Social Forces, 51(4), 448-454. https://doi.org/10.2307/2576690

Angle H. L., \& Perry J. L. (1981). An Empirical Assessment of Organizational Commitment and Organizational Effectiveness. Administrative Science Quarterly, 26(1), 1-14. https://doi.org/10.2307/2392596

Angle, H. L., \&Perry, J. L. (1983). An empirical assessment of organizational commitment scales. Personnel Psychology, 36, 87-98. https://doi.org/10.1111/j.1744-6570.1983.tb00505.x

Becker T. E. (1992). Bases of Commitment: Are They Distinctions worth Making? Academy of Management Journal, 35(1), 232-244.

Becker T. E., Billings R. S., Eveleth D. M. et al. (1996). Foci and Bases of Employee Commitment: Implications for Job Performance. Academy of Management Journal, 39(2), 464-482.

Becker, H. A. (1960). Notes on the concept of commitment. American Journal of Sociology, 66, 45-48. https://doi.org/10.1086/222820

Eby, L. T., Freeman, D. M., Rush, M. C. et al. (1999).Motivational Bases of Affective Organizational Commitment: A Partial Test of an Integrative Theoretical Model. Journal of Occupational and Organizational Psychology, 72(4), 463- 483. https://doi.org/10.1348/096317999166798

Mowday, R. T., Steers, R. M., \& Porter, L. W. (1979). The measurement of organizational commitment. Journal of Vocational Behavior, 14, 68-75. https://doi.org/10.1016/0001-8791(79)90072-1

Porter, L. W., Steers, R. M., \& Mowday, R. T. (1974). Organization commitment, job satisfaction, and resignation among psychiatric technicians. Journal of Applied Psychology, 59, 611-617. https://doi.org/10.1037/h0037335

Ritzer, G., \& Trice H. M. (1969). Empirical Study of Becker, H Side-Bet Theory. Social Forces, 47(4), 475-478. https://doi.org/10.2307/2574537

Somers, M. J. (1995). Organizational Commitment, resignation and Absenteeism: An Examination of Direct and 
Interaction Effects. Journal of Organizational Behavior, 16(1), 49-58. https://doi.org/10.1002/job.4030160107

Steers, R. M. (1977). Antecedents and Outcomes of Organizational Commitment. Administrative Science Quarterly, 22(1), 46-56. https://doi.org/10.2307/2391745

Sun, D., Xue, L., \& Zhang, L. P. (2021). Analysis of the diffusion mechanism of emerging technology risk perception. Science Research, 39(1), 2-11.

Tsoumbris, P., \& Xenikou, A. (2010). Commitment Profiles: The Configural Effect of the Forms and Foci of Commitment on Work Outcomes. Journal of Vocational Behavior, 77(3), 401-411. https://doi.org/10.1016/j.jvb.2010.07.006

Zeng, D. M., Zou, S. M., \& Zhang, Y. S. (2020). Research on the Pricing Model of High-tech Enterprise Innovation Ecosystem. China Science and Technology Forum, 5, 30-35.

Zhang, Y. S. (2019).Analysis of the boundary and structure of the innovation ecosystem of high-tech enterprises. Soft Science, 11, 95-97+102.

Zhang, Y. S., \& Zou, S. M. (2020). Research on the Governance Mechanism of High-tech Enterprise Innovation Ecosystem. Research in Science of Science, 5, 785-792.

\section{Copyrights}

Copyright for this article is retained by the author(s), with first publication rights granted to the journal.

This is an open-access article distributed under the terms and conditions of the Creative Commons Attribution license (http://creativecommons.org/licenses/by/4.0/). 